\title{
Belgeo
}

Revue belge de géographie

4 | 2005

Miscellaneous

\section{Smith Stephen, Atlas de l'Afrique, un continent jeune, révolté, marginalisé}

Paris, Autrement, 2005, 80 p.

\section{Julien Vandeburie}

\section{CpenEdition}

\section{Journals}

Édition électronique

URL : http://journals.openedition.org/belgeo/12239

DOI : $10.4000 /$ belgeo.12239

ISSN : 2294-9135

\section{Éditeur :}

National Committee of Geography of Belgium, Société Royale Belge de Géographie

\section{Édition imprimée}

Date de publication : 31 décembre 2005

Pagination : 525-526

ISSN : 1377-2368

\section{Référence électronique}

Julien Vandeburie, «Smith Stephen, Atlas de l'Afrique, un continent jeune, révolté, marginalisé », Belgeo [En ligne], 4 | 2005, mis en ligne le 29 octobre 2013, consulté le 22 septembre 2020. URL : http:// journals.openedition.org/belgeo/12239; DOI : https://doi.org/10.4000/belgeo.12239

Ce document a été généré automatiquement le 22 septembre 2020

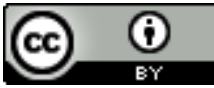

Belgeo est mis à disposition selon les termes de la licence Creative Commons Attribution 4.0 International. 


\section{Smith Stephen, Atlas de l'Afrique, un continent jeune, révolté, marginalisé}

Paris, Autrement, 2005, 80 p.

Julien Vandeburie

\section{RÉFÉRENCE}

Smith Stephen, Atlas de l'Afrique, un continent jeune, révolté, marginalisé, Paris, Autrement, $80 \mathrm{p}$.

1 Un atlas sur l'Afrique est a priori une bonne idée. Malgré un bon nombre d'ouvrages généraux consacrés à l'Afrique comme Continent pluriel dirigé par F. Bart, il restait à réaliser un atlas sur l'Afrique.

2 Il s'agit d'un atlas commenté et le sous-titre de l'atlas: un continent jeune, révolté, marginalisé annonce l'orientation prise par l'auteur; on pourrait presque renommer l'ouvrage Atlas géopolitique de l'Afrique. Cartes, graphiques, textes et citations composent des thèmes développés en double page.

3 La première partie (un continent pluriel) rassemble ce que l'on trouve dans un atlas classique: milieu naturel (avec un excellent graphique des milieux climatiques, des productions agricoles et de l'organisation humaine); infrastructures de communication, démographie (avec une carte des densités par pays, ce qui ne veut pas dire grand-chose de la répartition de la population); ethnies (on est étonné de ne pas voir apparaitre les Hutus et les Tutsis mais des Rwanda et Rundi) ; diversité linguistique (une carte du nombre de langues incompréhensible); économie, endettement et insertion mondiale (certes un thème intéressant mais trop peu développé car limité à la période post-coloniale ; pauvreté et sécurité alimentaire ; éducation et santé.

4 A partir de la seconde partie (le poids du passé), l'atlas présente des thèmes dans un ordre chronologique. L'histoire pré-coloniale souligne la longue présence de l'Etat en Afrique. Un thème développe la traite négrière, un autre l'exploration du continent par les Européens. Les thèmes suivants analysent la mise en place de la colonisation et ses 
résistances. Avec la décolonisation commence la troisième partie de l'ouvrage: l'Afrique comme enjeu de la rivalité est-ouest. L'auteur développe les thèmes de la Françafrique, de l'apartheid, des richesses minières, des conflits de substitution, de l'aide au développement, en soulignant l'aspect intéressé de cette dernière par l'intelligente citation de Peter Bauer qui définissait l'aide publique comme un « transfert de gouvernement à gouvernement, qui consiste à imposer les pauvres dans des pays riches pour soutenir le mode de vie des riches dans les pays pauvres» (p. 7).

5 L'après-guerre froide forme la quatrième partie de l'ouvrage et commence par faire le point sur la crise de l'Etat post-colonial, devenant dans certains cas un Etat fantôme. Ensuite, l'analyse s'attarde sur la démocratisation du continent avec un graphique retraçant les types de pouvoir en place, malheureusement difficile à lire et assorti d'une mauvaise cartographie. Un thème sur les guerres de fragmentation (dont on ne sait rien) et la logique génocidaire s'accompagne d'un autre sur les trafics illicites et la criminalisation. La quatrième partie se termine sur le thème de la pression migratoire, dont l'auteur souligne bien la dimension intrarégionale, et sur le thème de l'humanitaire en Afrique.

6 Le titre de la cinquième partie, le nouvel ordre civilisationnel, m'apparaît curieux, parce qu'aucune référence théorique n'est faite quant à cette orientation et parce que son contenu ne correspond pas à l'idée que l'on s'en fait. Certes, commencer par l'insertion terroriste de l'Afrique semble être dans l'air du temps, mais la question du pétrole n'apparaît pas à sa place - sauf à dévoiler les véritables enjeux. Les autres thèmes recouvrent des questions essentielles, introduits d'une manière cohérente (pluralisme et antagonismes religieux, SIDA, intégration régionale), ou non (écologie, avenir de l'Afrique du sud).

7 Ceci dit, l'atlas, malgré de bonnes intentions, est loin d'être parfait. L'information est lacunaire et parfois contradictoire. Si l'on veut comprendre le génocide rwandais entre Hutus et Tutsis, comment une carte sur les ethnies peut-elle ne pas les distinguer? On ne comprend pas non plus très bien les liens entre richesses minières et conflits, et les informations sur le monde rural sont éparses et difficiles à recouper. L'atlas contient aussi beaucoup d'informations non exploitées et non expliquées: que sont les bantoustans? Que font les expatriés français en Afrique?

8 Et il compte de nombreuses fautes, erreurs, coquilles qui finissent par être désagréables. L'arabe est-il endogène en République Centrafricaine? L'anglais en Guinée-Bissau et le portugais en Gambie? (p.19) Livingstone meurt en 1873, alors pourquoi lui imputer une expédition entre 1873 et 1877 ? (p. 30) Pourquoi intituler la carte de la page 34 "foyers de révolte au XIX siècle", alors qu'elle contient des données de la deuxième moitié du XX $\mathrm{XX}^{\mathrm{e}}$ ? Dans le commentaire de la page 35 , l'Afrique aurait été le seul continent passé presque intégralement sous domination étrangère durable, l'auteur ignore-t-il donc l'histoire de l'Amérique latine ? Et dire que le Kenya et l'Angola ont été des colonies de peuplement au même titre que l'Algérie et l'Afrique $\mathrm{du}$ sud est un peu fort. Page 38, le Mozambique n'est plus une ancienne colonie portugaise; page 45 l'Unita et le gouvernement sont inversés; page 52 une carte par plage avec en nombre absolu les morts dus aux conflits; page 56 même chose avec le nombre de réfugiés ; page 57 , dans quelle devise sont libellés les montants du tableau? Si l'information sur les groupes évangélistes est certes intéressante, quelle est son utilité dans cet atlas? On n'apprend rien sur leur localisation, leur nombre et leurs stratégies d'implantation. Page 69, la légende est lacunaire, page 76, les statistiques 
doivent être déchiffrées (décalage dans les colonnes). Enfin, les notices biographiques sont curieuses : faire côtoyer des explorateurs européens, des responsables africains, des chercheurs et essayistes avec Georges Bush, Diderot et André Gide reste étonnant.

9 En conclusion, la lecture de cet atlas se doit d'être attentive. Partant de bonnes intentions et réunissant des sources intéressantes, le résultat est mitigé : des informations pertinentes côtoient des analyses poussives et incomplètes. 